\title{
Urban Heating System Reform and Environmental Kuznets Curve: Based on the Analysis of Provincial Panel Data from 2000 to 2013
}

\author{
Wang Haiqing \\ Si Chuan University \\ Chengdu, China \\ 453153246@qq.com
}

\begin{abstract}
Based on the econometric test of environmental kuznets EKC effect, a discrete model is proposed to describe the relationship between economic growth and pollutant emission. This model is used to analyze the policy of "guiding opinions on the reform of urban heating system" implemented by China in 2003, and to observe whether the policy can bring the effect of energy-saving and emission reduction. Since the heating system is closely related to sulfur dioxide emissions, this paper takes sulfur dioxide as a typical pollutant, analyzes the changes of economic growth level and sulfur dioxide emissions in the provinces and municipalities involved in the heating system reform from 2003 to 2013, and compares that with non-pilot province and all provinces as well as with the same pilot provinces from 2000 to 2002.The empirical results show that, first of all, the inflection point of the inverted u-shaped curve indeed moved to the left compared that before 2003. Second, after comparing pilot provinces with non-pilot provinces and all provinces after 2003 , it was found that the environmental Kuznets curve moved slightly to the left compared with non-pilot provinces and all provinces. It can be seen from the graph that the order of crossing the inflection point is pilot provinces, all provinces and non-pilot provinces, indicating that this policy had indeed brought some positive effects and achieved the effect of energy conservation and emission reduction.
\end{abstract}

Keywords-Economic growth; Sulfur dioxide emission; Environmental Kuznets curve (EKC); Panel data estimation; Policy evaluation

\section{INTRODUCTION}

In the past 30 years of reform and opening up, China has ushered in a period of rapid economic development. However, the rapid economic growth has also brought inevitable environmental damage of varying degrees. The dilemma and conflict between ecological environment deterioration and economic development have attracted increasing attention. In fact, as the development practices of most developing countries and newly industrialized countries have shown, environmental degradation and resource depletion are important problems in economic take-off. On the one hand, as a result of the exploitation and utilization of natural resources and the increasing emission of industrial pollutants, economic growth has led to the negative effects of environmental quality degradation. On the other hand, the depletion of resources and environmental degradation, in turn, inhibit the long-term sustainable economic growth.

Economists have done a lot of research on the relationship between economic development and environmental pollution. Back in the early 1970s, the club of Rome put forward the "extreme growth theory" -- the idea that economic growth would be restricted by natural resources and such an economic model would not be sustainable. Therefore, in order to protect the environment, economic growth must be slowed down. Kuznets (1955) proposed the famous inverted u-shaped curve between income distribution and economic development, namely at the beginning of the economic development process, especially when the national income per capita rises from the lowest to moderate levels, income distribution first tends to deteriorate in the beginning, then improves with the economic development and finally achieves fair income distribution, showing the inverted $U$ shape. Some scholars continue to wonder if there is an inverted u-shaped curve between economic growth and environmental quality. Grossman and Krueger (1991), when analyzing the environmental effect of the North American free trade area agreement (NAFTA), empirically investigated the existence of the u-shaped relationship between environment and income for the first time. In this influential paper, Grossman and Krueger explained the emergence of EKC from three action channels that economic growth affects environmental quality: economic development means greater economic activity and demand for resources, which has negative scale effects on the environment; but at the same time, economic development has reduced pollution emissions and improved environmental quality through positive technological advances (such as the use of more environmentally friendly new technologies) and structural effects (such as the upgrading and optimization of industrial structures).Therefore, these three effects jointly determine the inverted $\mathrm{u}$-shaped curve relationship between economic development and environmental quality: that is, when a country's economic development level is low, the degree of environmental pollution is relatively low. However, with the increase of per capita income, the level of environmental pollution increases from low to high. When economic development reaches a certain level, that is to say, after reaching a certain critical point or "inflection point", with the 
further increase of per capita income, the degree of environmental pollution gradually slows down, and environmental quality is gradually improved. Inspired by the above point of view, scholars from various countries have used cross section, time series or panel data to conduct extensive studies on the existence of Environmental Kuznets Curve (EKC).

In China, Bao Qun and Peng Shuijun (2006) believed that economic development and the environment are mutually rewarding. Therefore, the simultaneous equation model was adopted for analysis, where five of the six types of pollutants examined were found to be an inverted u-shape. Cai Le (2008) at al. estimated the EKC of China's sulfur dioxide, believing that the east has passed the inflection point while the west was still in the rising phase of the curve. In China, the problem of environmental pollution has become an urgent problem to be solved.

The environmental pollution problem covers a wide range. This paper will only focus on the pollution of sulfur dioxide in the atmosphere. Sulfur dioxide is a major component of acid rain, which is harmful to human health, animals and plants and can corrode buildings and acidify soil, rivers and lakes. According to the 2008 annual report on environmental statistics, China is now the world's largest emitter of sulfur dioxide, with emissions reaching 25.88 million tons in 2006 and falling every year since then. The emissions in 2008, however, still exceeded 20 million tons. The second-level air sulfur dioxide concentration standard in China is 60 micrograms per cubic meter, which is the national standard that cities must meet and the minimum standard for protecting human health. However, in 2008, more than $40 \%$ of cities did not meet the second-level standard, which is one of the most urgent air pollution problems demanding prompt solution in China.

In recent years, with the increasingly serious global warming, carbon emissions have become a hot area and a large number of relevant literatures have emerged, such as Lin Boqiang (2010) and Zhang Youguo (2010). It needs to be pointed out that carbon dioxide emissions will not cause immediate harm, and its harm is long-term and the consequences will be shared by all mankind. Sulfur dioxide, however, is easily soluble in water. Sulfur dioxide emissions from economic activities fall to the ground with rainfall. Its hazard is not easily transferred to other countries and the consequences will largely be borne by the emitters themselves. Therefore, studying and reducing sulfur dioxide pollution is a more urgent and severe task for China. From the 12th five-year plan we can see that China should speed up the building of a resource-saving and environment-friendly society, raise the level of ecological civilization, and focus on energy conservation in key areas such as industry, construction and transportation.

The breakthrough point in this paper is to study the building heating system. In 2003, the government issued a document entitled Guiding Opinions on the Reform of Urban Heating System, partly to encourage energy conservation and reduce pollutants emissions. In order to study the validity of the document, this article starts with sulfur dioxide, firstly to verify if there is a change in its emissions before and after 2003 and if the EKC will move to the left, secondly to study the difference of Kkuznets curve between pilot provinces, non-pilot provinces and all provinces from 2003 to 2013. If the left shift of the provincial curve involved in the heating system reform after 2003 is greater than that of non-pilot provinces and all provinces, it can be inferred that the policy has a certain effect on energy conservation and emission reduction and vice versa.

\section{ECONOMETRIC TEST OF EKC EFFECT}

\section{A. Data Collection}

In this paper, panel data including both cross section data and time series data are adopted in the empirical analysis for two main reasons: First, in terms of sample data volume, panel data contains more data points, which brings greater freedom, and the combination of section variables and time series variables can significantly reduce the problems caused by default variables. More importantly, the environment-income EKC shape not only has the characteristics of timing dimension, but also has the characteristics of section dimension. Therefore, panel data combining time-series and cross-sectional information can reflect the comprehensive impact of changes in income levels and regional development differences on the environment-income relationship.

According to the availability of data and the research requirements of this paper, the panel data of this paper collected the original data of per capita GDP (yuan) and co2 emissions (10,000 tons) related to 32 provincial administrative regions (except Hong Kong and Macao special administrative regions) from 2000 to 2013. Considering that in the empirical literature on the relationship between environmental quality and income change, pollutant emissions are often used for research, sulfur dioxide emission index is used to measure environmental pollution in this paper. Data sources are compiled and calculated from the corresponding issues of The Statistical Bulletins on National Economic and Social Development, The Environmental Statistical Bulletins of Various Regions and the China Environmental Statistical Yearbook. Income change in this paper is measured by per capita income index, because compared with total income, per capita income can more easily reflect the impact of real income level change on environmental quality, and the demand preference effect of income change on environmental quality is mainly reflected in personal income change.

The per capita income of each region in this paper is measured by per capita GDP, and the data are collected and calculated by the China Statistical Yearbook over the years. 
TABLE I. DESCRIPTIVE STATISTICS

\begin{tabular}{|c|c|c|c|c|}
\hline & Mean Value & Variance & $\begin{array}{c}\text { Maximu } \\
\mathrm{m}\end{array}$ & Minimum \\
\hline $\begin{array}{c}\text { Sulfur dioxide } \\
\text { emissions }\end{array}$ & 71.1265 & 46.1816 & 200.3 & 0.0749 \\
\hline & & & & \\
\hline $\begin{array}{c}\text { GDP per } \\
\text { capita }\end{array}$ & 23424.73 & 18585.05 & 99607 & 2759 \\
\hline
\end{tabular}

\section{B. Model}

Considering the specific difference of panel data in the cross-section dimension, that is, due to the difference of economic development degree and other economic factors among different provinces, we added the cross-section fixed effect in the estimation equation to reflect the specific difference of different economic regions.

A quadratic function is usually used in existing literature to describe the relationship between pollutant discharge and economic growth, and the validity of EKC hypothesis can be tested by the following equation:

$$
y_{i t}=\beta_{0}+\beta_{1} x_{i t}+\beta_{2} x_{i t}{ }^{2}+\varepsilon_{i t}+\mu_{i}
$$

Among them, $y_{i t}$ represents the pollution emission of the $\mathrm{i}$ province in year $\mathrm{t}$ and it is the sulfur dioxide emission. $\varepsilon_{i t}$ is the regression error on the time series and cross sections. $\mu_{i}$ is the random error of the section.

In the theoretical symbol of the parameter in the equation, the symbol of the complement $\beta_{1}$ is expected to be positive. If the symbols of $\beta_{2}$ is expected to be negative and the statistical results are significant, it indicates that there is an EKC effect between environmental quality and economic growth. According to the regression results of equation (1), we can calculate the turning point (TP) of the environmental Kuznets inverted $\mathrm{u}$-shaped curve as

$$
x^{*}=-\beta_{1} / 2 \beta_{2}
$$

\section{Panel Model Selection and Regression}

1) verify whether there is an EKC in the cities that participated in the heating system reform from 2003 to 2013:

The regression equation is obtained by using panel fixing model:

$$
\mathrm{y}_{\mathrm{t}}=6.417+2.001 \mathrm{x}_{\mathrm{t}}-2.298 \mathrm{x}_{\mathrm{t}}^{2}
$$

\begin{tabular}{|c|c|}
\hline Pollution Parameter & $\mathrm{SO} 2$ \\
\hline $\begin{array}{c}\text { Estimation Model } \\
\text { C }\end{array}$ & $\begin{array}{l}\text { Panel Fixing Model } \\
6.417^{*} \\
(2.457)\end{array}$ \\
\hline GDP Per Capita & $\begin{array}{l}2.001 * * \\
(0.023)\end{array}$ \\
\hline GDP $^{2}$ Per Capita & $\begin{array}{c}-2.298 * * * \\
(0.015)\end{array}$ \\
\hline $\mathrm{R}^{2}$ & 0.949 \\
\hline D.W & 0.569 \\
\hline Sample & 157 \\
\hline The Curve Shape & Inverted u-shaped \\
\hline Inflection Point & 4354 \\
\hline
\end{tabular}

TABLE II. RESULTS OF THE PILOT PROVINCES' REGRESSION FROM 2003 TO 2013

The symbols of regression coefficients accord with the theoretical expectation. According to the regression results, it can be estimated that the per capita GDP of sulfur dioxide emissions in China at the turning point of EKC is 4,354 yuan/person, which means that before the per capita GDP of China's pilot provinces reached 4,354 yuan per capita, with the increase of per capita income, environmental pollution degree has risen from low to high, and environmental degradation has been aggravated with economic growth. When the economic development reached 4,354 yuan per capita, with the further increase of per capita income, the degree of environmental pollution gradually slowed down from high to low, and the environmental quality gradually be improved.

The significance test of regression coefficient shows that each regression coefficient has passed the significance test, which is significant at $10 \%$ significance level. Therefore, statistical test of regression equation supports the hypothesis that there is significant EKC effect between sulfur dioxide emissions and economic growth in pilot provinces.

2) Verify the existence of EKC in non-pilot provinces from 2003 to 2013 and compare it with pilot provinces:

The regression equation is obtained by using panel fixing model:

$$
\mathrm{y}_{\mathrm{t}}=5.093+1.260 \mathrm{x}_{\mathrm{t}}-1.211 \mathrm{x}_{\mathrm{t}}^{2}
$$


TABLE III. RESULTS OF THE REGRESSION OF NON-PILOT PROVINCES FROM 2003 TO 2013

\begin{tabular}{|c|c|}
\hline Pollution Parameter & SO2 \\
\hline Estimation Model & Panel Fixing Model \\
$\mathrm{C}$ & $5.093^{*}$ \\
& $(1.435)$ \\
\hline GDP Per Capita & $1.260^{* *}$ \\
& $(0.007)$ \\
\hline GDP $^{2}$ Per Capita & $-1.211^{* * *}$ \\
& $(0.097)$ \\
\hline $\mathrm{R}^{2}$ & 0.949 \\
\hline $\mathrm{D} . \mathrm{W}$ & 0.775 \\
\hline Sample & 157 \\
\hline The Curve Shape & Inverted u-shaped \\
\hline Inflection Point & 5206 \\
\hline b. & $\begin{array}{c}* * * * * * \text { represents the significance levels of 1\%, 5\% and 10\% respectively. The t } \\
\text { statistic value of the estimated coefficient is calculated according to the White robust standard } \\
\text { deviation }\end{array}$ \\
\hline
\end{tabular}

The symbols of regression coefficients accord with the theoretical expectation. According to the regression results, it can be estimated that the per capita GDP of sulfur dioxide emissions in China at the turning point of EKC is 5206 yuan/person, which means that before the per capita GDP of China's pilot provinces reached 5206 yuan, with the increase of per capita income, environmental pollution degree has risen from low to high, and environmental degradation has been aggravated with economic growth. When the economic development reached 5206 yuan per capita, with the further increase of per capita income, the degree of environmental pollution gradually slowed down from high to low, and the environmental quality gradually be improved.

The significance test of regression coefficient shows that each regression coefficient has passed the significance test, which is significant at $10 \%$ significance level. Therefore, statistical test of regression equation supports the hypothesis that there is significant EKC effect between sulfur dioxide emissions and economic growth in non-pilot provinces.

Comparing its inflection point with that of pilot provinces, based on the data from 2003 to 2013 , it can be seen that pilot provinces cross the inflection point earlier than non-pilot provinces, and the environmental pollution degree of pilot provinces gradually slow down earlier, achieving the common progress of economy and environment.

3) Verify the existence of EKC in all provinces from 2003 to 2013 and compare it with pilot provinces: model:

The regression equation is obtained by using panel fixing $\mathrm{yt}_{\mathrm{t}}=8.232+2.257 \mathrm{x}_{\mathrm{t}}-2.284 \mathrm{x}_{\mathrm{t}}^{2}$
TABLE IV. RESULTS OF THE REGRESSION OF ALL PROVINCES FROM 2003 TO 2013

\begin{tabular}{|c|c|}
\hline Pollution Parameter & $\mathrm{SO} 2$ \\
\hline $\begin{array}{c}\text { Estimation Model } \\
\text { C }\end{array}$ & $\begin{array}{c}\text { Panel Fixing Model } \\
8.232^{*} \\
(3.613)\end{array}$ \\
\hline GDP Per Capita & $\begin{array}{c}2.257 * * \\
(0.571)\end{array}$ \\
\hline $\mathrm{GDP}^{2}$ Per Capita & $\begin{array}{c}-2.284 * * * \\
(0.731)\end{array}$ \\
\hline $\mathrm{R}^{2}$ & 0.955 \\
\hline D.W & 0.7383 \\
\hline Sample & 314 \\
\hline The Curve Shape & Inverted u-shaped \\
\hline Inflection Point & 4934 \\
\hline
\end{tabular}

The symbols of regression coefficients accord with the theoretical expectation. According to the regression results, it can be estimated that the per capita GDP of sulfur dioxide emissions in China at the turning point of EKC is 4934 yuan/person, which means that before the per capita GDP of China's pilot provinces reached 4934yuan, with the increase of per capita income, environmental pollution degree has risen from low to high, and environmental degradation has been aggravated with economic growth. When the economic development reached 4934 yuan per capita, with the further increase of per capita income, the degree of environmental pollution gradually slowed down from high to low, and the environmental quality gradually be improved.

The significance test of regression coefficient shows that each regression coefficient has passed the significance test, which is significant at $10 \%$ significance level. Therefore, statistical test of regression equation supports the hypothesis that there is significant EKC effect between sulfur dioxide emissions and economic growth in all provinces.

Comparing its inflection point with that of pilot provinces and non-provinces, based on the data from 2003 to 2013, it can be seen that pilot provinces cross the inflection point earlier than all provinces, and all provinces earlier than non-pilot provinces, which is in line with the expected estimation and achieves the common progress of economy and environment.

4) Verify the existence of EKC in pilot provinces from 2000 to 2003 and compare it with pilot provinces from 2003 to 2013:

The regression equation is obtained by using panel fixing model:

$$
\mathrm{yt}_{\mathrm{t}}=4.174+2.409 \mathrm{xt}_{\mathrm{t}}-2.122 \mathrm{xt}^{2}
$$


TABLE V.

RESULTS OF THE REGRESSION OF ALL PROVINCES FROM 2000 TO 2002

\begin{tabular}{|c|c|}
\hline Pollution Parameter & SO2 \\
\hline Estimation Model & Panel Fixing Model \\
$\mathrm{C}$ & $4.174^{*}$ \\
& $(6.272)$ \\
\hline GDP Per Capita & $2.409^{* *}$ \\
& $(0.001)$ \\
\hline GDP $^{2}$ Per Capita & $-2.122^{* * *}$ \\
& $(0.002)$ \\
\hline $\mathrm{R}^{2}$ & 0.9978 \\
\hline D.W & 1.7751 \\
\hline Sample & 93 \\
\hline The Curve Shape & Inverted u-shaped \\
\hline Inflection Point & 5679 \\
\hline
\end{tabular}

$*, * *, * * *$ represents the significance levels of $1 \%, 5 \%$ and $10 \%$ respectively. The $t$ statistic value of the estimated coefficient is calculated according to the White robust standard deviation

The symbols of regression coefficients accord with the theoretical expectation. According to the regression results, it can be estimated that the per capita GDP of sulfur dioxide emissions in China at the turning point of EKC is 5679 yuan/person, which means that before the per capita GDP of China's non-pilot provinces reached 5679 yuan, with the increase of per capita income, environmental pollution degree has risen from low to high, and environmental degradation has been aggravated with economic growth. When the economic development reached 5679 yuan per capita, with the further increase of per capita income, the degree of environmental pollution gradually slowed down from high to low, and the environmental quality gradually be improved.

The significance test of regression coefficient shows that each regression coefficient has passed the significance test, which is significant at 5\% significance level. Therefore, statistical test of regression equation supports the hypothesis that there is significant EKC effect between sulfur dioxide emissions and economic growth in all provinces.

Comparing with the inflection point, it can be seen that pilot provinces crossed the inflection point earlier after 2003, and the inflection point of Kuznets curve moved to the left, which is in line with the expected estimation. It can be also seen that the implementation of the policy has indeed brought about the positive effect of energy conservation and emission reduction, and it can realize the win-win situation of economic progress and environmental protection earlier.

From what has been discussed above, we know that: after 2003, there were 14 heating pilot cities including Beijing, Tianjin, Hebei, Inner Mongolia, Heilongjiang, Jilin, Liaoning, Shandong, Henan, Shanxi, Gansu, Ningxia, Qinghai and Xinjiang implementing the urban heating system reform. We will compare these 14 cities in two ways: First, the change of environmental kuznets curve (EKC) around 2003; Second, the comparison of environmental kuznets curve (EKC) between the national level, non-pilot provinces and 14 pilot provinces in the same period after 2003.
Based on a large number of previous literature (e.g., Peng Shuijun (2005)) and the argumentation in this paper, the environmental Kuznets inverted u-shaped curve relationship largely depends on the selection of pollution index and estimation method. When the EKC selects $\mathrm{SO} 2$ as pollutant index for EKC test, the curve is inverted U shape.

First, the data from 2000 to 2002 and 2003 to 2013 were compared to see whether the EKC had moved. According to the analysis, the inflection point of the pilot province from 2003 to 2013 was 4,354 yuan/person, and the inflection point from 2000 to 2002 was 5,679 yuan/person. The left shift of the inflection point indicates that the implementation of a series of policies is conducive to environmental protection. The EKC will cross the inflection point earlier to achieve a win-win situation between economy and environment.

Secondly, comparing the EKC of the national level, nonpilot provinces and pilot provinces in the same period since 2003 to observe whether there is any difference between pilot and non-pilot provinces after the implementation of the policy. From 2003 to 2013, the pilot provincial inflection point was 4,354 yuan/person, the non-pilot provincial inflection point was 5,206 yuan/person; all the provincial inflection points were 4,943 yuan/person. The order of crossing the inflection point is pilot provinces, all provinces and non-pilot provinces, which conforms to the expected inference of effective policy implementation. After the implementation of the policy, the inflection point moved to the left compared with the same level in the same period, indicating that the reform policy of urban heating system is effective. According to the data, 14 pilot cities have achieved the goal of energy conservation and emission reduction and promoted the green economy, meeting the target of the 12th five-year plan.

\section{CONCLUSIONS AND POLICY RECOMMENDATIONS}

Based on panel data of 32 provincial-level administrative regions (except Hong Kong and Macao special administrative regions) in China from 2000 to 2013 and econometric tests on the EKC effect of environmental Kuznets, this paper uses panel fixing model and tries to test whether the policy implementation of "the reform of urban heating system" is effective. According to the horizontal and vertical comparison of the empirical results, we find that the implementation of the policy indeed brings the left shift of the curve turning point, which can realize the win-win situation of economy and environment earlier.

The academic value and practical significance of the findings are as follows: at the government level, in the past, the assessment system with the single GDP as the incentive mechanism was popularly implemented, which was easy to cause environmental problems in order to promote economic development. Therefore, the test results in this paper make up for this deficiency, and it is believed that the promotion mechanism of the government should consider environmental factors into the performance evaluation to promote the development of green economy. At the industrial level, the development of industries with low pollution, low energy consumption and low emission should be encouraged; the introduction, development and application of energy-saving 
and environmental protection technologies should be promoted and the development of clean energy should be accelerated. At the policy level, the former focused on economic benefits and lacked sufficient consideration of potential environmental issues. In the face of severe environmental pollution and resource shortage, we must strength crisis awareness, adopt a green and low-carbon development concept. Government should focus on energy conservation and emission reduction, improve incentive and restraint mechanisms, accelerate the speed of building a resource-saving and environment-friendly production and consumption patterns and enhance the capacity for sustainable development.

\section{REFERENCES}

[1] Grossman, G. M. \& Krueger, A. B.,1991,Environmental impacts of a North American Free Trade Agreement, National Bureau of Economic Research Working Paper 3914, NBER, Cambridge MA.

[2] Kuznets $S$.Economic Growth and Income Equality [J]. American Economic Review, 1955, 45(1):1 -28. 